Научная статья

УДК 598.23:591.5(571.5)

DOI: $10.18101 / 2542-0623-2021-4-65-71$

\title{
ПИТАНИЕ БОЛЬШОГО БАКЛАНА НА БАЙКАЛЕ В ПЕРИОД ВЫКАРМЛИВАНИЯ ПТЕНЦОВ
}

\section{М. С. Мокридина}

\author{
(C) Мокридина Мария Сергеевна \\ старший преподаватель, \\ Иркутский государственный университет \\ Россия, 664003, г. Иркутск, ул. Карла Маркса, 1 \\ rjs-92@mail.ru
}

\begin{abstract}
Аннотация. В статье приводятся данные по питанию птенцов большого баклана старшего возраста, собранные в различных районах Байкала (на Малом Море, в дельте p. Селенги и на о. Бакланий Камень, в окрестности бухты Песчаная) в 2016-2020 гг. Показано, что на различия в питании в большей степени влияет местоположение колонии, нежели условия того или иного года. На Малом Море основу питания баклана в гнездовой период составляют рыбы бычкового комплекса и соровые виды (окунь, елец, плотва). В дельте р. Селенги основу питания также составляют соровые виды рыб, среди которых преобладает ротан-головёшка, но в периоды подхода нагульных косяков омуля к дельте он переключается на питание омулем. На о. Бакланий Камень зафиксирован самый широкий спектр питания баклана, что определяется своеобразным положением острова. На этом острове и в дельте р. Селенги выявлена сезонность в питании. Ключевые слова: большой баклан, питание, Байкал, Малое Море, Селенга, о. Бакланий Камень.
\end{abstract}

\section{Для цитирования}

Мокридина М. С. Питание большого баклана на Байкале в период выкармливания птенцов // Природа Внутренней Азии. Nature of Inner Asia. 2021. № 4(19). С. 65-71. DOI: 10.18101/2542-0623-2021-4-65-71

\section{Введение}

Бакланы - облигатные, но не специализированные ихтиофаги, питающиеся любой доступной рыбой, которую в состоянии заглотить. Большой баклан Phalacrocorax phalacrocorax sinensis, когда-то многочисленный вид Байкала, затем исчезнувший с его берегов и в настоящее время вновь восстановившийся [Пыжьянова и др., 2015], не является исключением. Его вторичное появление на Байкале происходило на фоне существенной деградации промысловых рыбных запасов, что привело в 2017 г. к введению запрета на добычу омуля - основной промысловой рыбы на Байкале [Мокридина, 2021]. В то же время баклан не только внедрился в экосистему озера, но и стремительно наращивал свою численность здесь. В связи с этим встал вопрос: на каком ресурсе это могло произойти? Для ответа на него нами были собраны данные по питанию баклана в различных колониях на Байкале, результаты обработки которых представлены в настоящей статье. 


\section{Материал и методика}

Данные по питанию рыбоядных собраны в 2016-2020 гг. на различных островах Малого Моря, в дельте р. Селенги и на о. Бакланий Камень (район бухты Песчаная). Попытки собрать данные по питанию в 2021 г. не увенчались успехом, так как успешность размножения бакланов в доступных колониях была очень низкой [Пыжьянов, Мокридина, в печати] и птенцов соответствующего возраста в периоды посещения колоний не было найдено.

Основной материал по питанию большого баклана на Байкале собирался щадящим методом, основанном на поведенческих особенностях птенцов баклана, которые при стрессе отрыгивают пищу. В качестве источника стресса выступает сам наблюдатель: достаточно приблизиться к гнезду и птенцы от испуга отрыгивают пищу. Причем делают это даже в том случае, если гнездо находится в недоступном для наблюдателя месте, в частности на деревьях. Каждый отрыгнутый пищевой комок снабжался этикеткой, заворачивался в марлю и помещался в емкость с формалином. Дальнейшая его разборка проводилась в лабораторных условиях, где определялась общая масса пищевого комка, а так же масса составляющих его частей, разделенных по видам рыб. Полупереваренные остатки рыб, не поддающиеся определению, взвешивались отдельно. Следует сразу оговориться, что пищевые комки с сильно переваренными объектами мы старались не собирать. Для этого колонии посещались в сроки, когда в ней уже были подросшие птенцы, которых родители кормят цельной рыбой [Рябицев, 2008]. Колонии для сбора отрыжек лучше всего посещать во вторую половину дня, когда основная масса взрослых птиц уже вернулась с добычей и птенцы накормлены.

По нашему мнению, экстраполяция полученных данных на взрослых птиц вполне оправдана, так как питание птенцов старшего возраста, у которых и брались образцы, и взрослых особей у рыбоядных птиц сходно.

Общее количество анализируемого материала представлено в таблице 1 .

Таблийа 1

Общее количество собранных проб по годам и колониям

\begin{tabular}{|c|c|c|c|c|c|c|c|}
\hline \multirow{2}{*}{ № } & \multirow{2}{*}{ Район Байкала } & \multirow{2}{*}{ Колония (остров) } & \multicolumn{5}{|c|}{ Год } \\
\hline & & & 2016 & 2017 & 2018 & 2019 & 2020 \\
\hline 1 & \multirow{4}{*}{ Малое Море } & о. Едор & 25 & 20 & 31 & 29 & 2 \\
\hline 2 & & о. Изохой & 0 & 0 & 11 & 8 & 8 \\
\hline 3 & & о. Борокчин, север & 0 & 6 & 7 & 0 & 0 \\
\hline 4 & & о. Баргадагон & 0 & 0 & 0 & 0 & 3 \\
\hline 5 & бухта Песчаная & $\begin{array}{l}\text { о. Бакланий } \\
\text { Камень } \\
\end{array}$ & 28 & $43(23+20)^{*}$ & 24 & 24 & 22 \\
\hline 6 & дельта Селенги & протока Северная & - & - & - & 25 & 28 \\
\hline
\end{tabular}

* Материал был собран дважды: 23.06.2017 — 23 пробы, 18.07.2017 — 20 проб.

\section{Результаты и обсуждение}

При разборе материала с островов Малого Моря нами было найдено 9 видов рыб. Это представители байкальского бычкового комплекса - песчаная и каменная широколобки, желтокрылка, длиннокрылая широколобка, а также 
представители более глубинного рода Batrachacottus (определение до вида невозможно), соровые виды: речной окунь и елец и байкальские лососеобразные: омуль и белый байкальский хариус.

Надо отметить, что на качественный состав пищевых комков влияет местоположение островов. Так, например острова Едор и Изохой находятся в северной части Малого Моря и находятся по разные стороны пролива (под о. Ольхон и материком соответственно). Здесь мы наблюдаем более широкий спектр бычков, включая глубоководные виды (таблицы 2, 3). Острова Борокчин и Баргадагон находятся значительно южнее и, в отличии от первых двух, в непосредственной близости мелководных соров и озер, поэтому объемная доля сорового вида — окуня — здесь значительно выше (таблицы 4, 5).

Таблица 2

Характеристика питания птенцов большого баклана на о. Едор (Малое Море)

\begin{tabular}{|c|l|c|c|c|c|c|c|c|c|c|c|}
\hline \multirow{2}{*}{$№$} & \multicolumn{2}{|c|}{ Вид корма } & \multicolumn{4}{|c|}{ Встречаемость (\%) } & \multicolumn{5}{c|}{ Весовая доля (\%) } \\
\cline { 3 - 13 } & 2016 & 2017 & 2018 & 2019 & 2020 & 2016 & 2017 & 2018 & 2019 & 2020 \\
\hline 1 & $\begin{array}{l}\text { Песчаная } \\
\text { широколобка }\end{array}$ & - & 20 & 25,8 & 13,8 & - & - & 8,7 & 5,3 & 2,4 & - \\
\hline 2 & $\begin{array}{l}\text { Каменная } \\
\text { широколобка }\end{array}$ & 40 & 25 & 77,4 & 37,9 & 50 & 21,1 & 6,5 & 33,6 & 3,1 & 36 \\
\hline 3 & Желтокрылка & 80 & 85 & - & 89,7 & - & 43,2 & 58,6 & - & 45,6 & - \\
\hline 4 & $\begin{array}{l}\text { Длиннокрылая } \\
\text { широколобка }\end{array}$ & 20 & 5 & 6,5 & 31 & 50 & 9,6 & 1,6 & 1,6 & 10,8 & 64 \\
\hline 5 & $\begin{array}{l}\text { Бычки рода } \\
\text { Ватгасһасонти }\end{array}$ & 4 & 5 & 3,2 & - & - & 2,4 & 1 & 0,9 & - & - \\
\hline 6 & $\begin{array}{l}\text { Бычки, ближе } \\
\text { не определены }\end{array}$ & - & 20 & 3,2 & 10,4 & - & - & 7,3 & 0,8 & 2,3 & - \\
\hline 7 & Окунь речной & 16 & 5 & - & - & - & 14,8 & 3,6 & - & - & - \\
\hline 8 & Елец & - & 5 & - & - & - & - & 0,8 & - & - & - \\
\hline 9 & Омуль & - & - & 48,4 & 24,1 & - & - & - & 57,8 & 18,1 & - \\
\hline 10 & Хариус & - & 5 & - & 6,9 & - & - & 11,9 & - & 17,7 & - \\
\hline 11 & $\begin{array}{l}\text { Рыба, ближе } \\
\text { не определена }\end{array}$ & 12 & - & - & - & - & 8,9 & - & - & - & - \\
\hline
\end{tabular}

Таблища 3

Характеристика питания птенцов большого баклана на о. Изохой (Малое Море)

\begin{tabular}{|c|l|c|c|c|c|c|c|}
\hline \multirow{2}{*}{ № } & \multicolumn{2}{|c|}{ Вид корма } & \multicolumn{3}{|c|}{ Встречаемость (\%) } & \multicolumn{3}{c|}{ Весовая доля (\%) } \\
\cline { 3 - 8 } & 2018 & 2019 & 2020 & 2018 & 2019 & 2020 \\
\hline 1 & Песчаная широколобка & 36,4 & 12,5 & 37,5 & 9,2 & 4,3 & 9 \\
\hline 2 & Каменная широколобка & 81,9 & 25 & 75 & 75,6 & 2,3 & 76,9 \\
\hline 3 & Желтокрылка & - & 37,5 & 37,5 & - & 8,7 & 14,1 \\
\hline 4 & Длиннокрылая широколобка & 27,3 & - & - & 7 & - & - \\
\hline 5 & Род Ваtrachacottus & 9,1 & - & - & 8,2 & - & - \\
\hline 6 & Омуль & - & 87,5 & - & - & 84,7 & - \\
\hline
\end{tabular}


Характеристика питания птенцов большого баклана на о. Борокчин (Малое Море)

\begin{tabular}{|c|l|c|c|c|c|}
\hline \multirow{2}{*}{ № } & \multirow{2}{*}{ Вид корма } & \multicolumn{2}{|c|}{ Встречаемость (\%) } & \multicolumn{2}{c|}{ Весовая доля (\%) } \\
\cline { 3 - 6 } & & 2017 & 2018 & 2017 & 2018 \\
\hline 1 & Песчаная широколобка & - & 14,3 & - & 0,5 \\
\hline 2 & Каменная широколобка & - & 57,1 & - & 20,9 \\
\hline 3 & Желтокрылка & 83,3 & - & 76,6 & - \\
\hline 4 & Окунь речной & 16,7 & 42,9 & 23,4 & 59,1 \\
\hline 5 & Омуль & - & 28,6 & - & 19,5 \\
\hline
\end{tabular}

Таблица 5

Характеристика питания птенцов большого баклана на о. Баргадагон (Малое Море)

\begin{tabular}{|c|l|c|c|}
\hline \multirow{2}{*}{$№$} & \multicolumn{1}{|c|}{ Вид корма } & Встречаемость (\%) & Весовая доля (\%) \\
\cline { 3 - 4 } & & 2020 & 2020 \\
\hline 1 & Каменная широколобка & 100 & 57,5 \\
\hline 2 & Желтокрылка & 33,3 & 0,5 \\
\hline 3 & Окунь речной & 33,3 & 25 \\
\hline 4 & Рыба, ближе не определена & 33,3 & 17 \\
\hline
\end{tabular}

В таблицах 6 и 7 представлены данные собранные на острове Бакланий Камень и в дельте реки Селенга соответственно. Главным отличием от данных, полученных с Малого Моря, является наличие в питании баклана интродуцированного вида ротан-головешки. Этот вид весьма многочисленен в водоемах дельты p. Селенги, откуда он и начал свою экспансию в Байкал. Проник он и в водоемы на западном берегу озера, в частности в устье р. Голоустной. Таким образом, бакланы с острова Бакланий Камень могут добывать ротана как в дельте Селенги, так и в дельте р. Голоустная - расстояние от острова до этих мест практически одинаковое (правда кормовых полётов баклана через Байкал пока не зафиксировано). Так же в 2016 г. у птенцов с этой колонии в пище был найден один представитель рода Cyphocottus - это глубинные широколобки обитающие на глубине до 600 м.

Здесь же мы обнаружили сезонность питания большого баклана. В 2017 г. нам удалось собрать материал дважды: 23 июня и 18 июля. Так в июне, во время массового лета ручейника, в пище бакланов присутствует большое количество хариуса, а в июле его не обнаружено (см. табл. 6).

Сезонность в питании выявлена и в дельте р. Селенги. В 2020 г. данные по питанию собраны в середине июня, ещё до прихода нагульных косяков омуля к дельте, поэтому омуль занимает весьма скромное место в питании птенцов. А основу питания составляет ротан-головешка - не стайный вид, но равномерно распрееленный по дельте. Годом раньше колонию поселили в конце июня, как раз 
в момент массового подхода омуля к дельте. А добывать стайную рыбку намного легче, чем одиночных особей, поэтому бакланы в большей частьюи переключились на омуля, доля которого в этот период доходит до 90\% по весу.

Таблица 6

Характеристика питания птенцов большого баклана на о. Бакланий Камень (бухта Песчаная)

\begin{tabular}{|c|c|c|c|c|c|c|c|c|c|c|c|c|c|}
\hline \multirow{3}{*}{ № } & \multirow{3}{*}{ Вид корма } & \multicolumn{6}{|c|}{ Встречаемость (\%) } & \multicolumn{6}{|c|}{ Весовая доля (\%) } \\
\hline & & \multirow{2}{*}{$\stackrel{\circ}{\stackrel{i}{\sim}}$} & \multicolumn{2}{|c|}{$\hat{\bar{i}}$} & \multirow{2}{*}{$\stackrel{\infty}{\stackrel{\infty}{*}}$} & \multirow{2}{*}{ 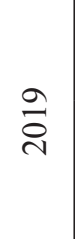 } & \multirow{2}{*}{ ઠิ } & \multirow{2}{*}{$\stackrel{0}{\stackrel{0}{*}}$} & \multicolumn{2}{|r|}{ 홍 } & \multirow{2}{*}{$\stackrel{\infty}{\stackrel{i}{i}}$} & \multirow{2}{*}{$\frac{a}{\stackrel{े}{~}}$} & \multirow{2}{*}{ ๙ิे } \\
\hline & & & 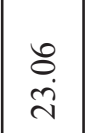 & $\begin{array}{l}\hat{0} \\
\infty \\
\infty\end{array}$ & & & & & $\begin{array}{l}\stackrel{8}{\sim} \\
\ddot{v}\end{array}$ & $\begin{array}{l}\hat{0} \\
\infty \\
\infty\end{array}$ & & & \\
\hline 1 & $\begin{array}{l}\text { Песчаная } \\
\text { широколобка }\end{array}$ & 17,9 & 21,7 & 15 & 62,5 & 37,5 & 4,6 & 8,2 & 8,1 & 8 & 29,7 & 11,4 & 1,5 \\
\hline 2 & $\begin{array}{l}\text { Каменная } \\
\text { широколобка }\end{array}$ & 75 & 8,7 & 10 & 54,2 & 54,2 & 45,5 & 40,8 & 2,8 & 1,8 & 22,9 & 34,2 & 23,3 \\
\hline 3 & Желтокрылка & 32,1 & 47,8 & 70 & 20,8 & 54,2 & 59,1 & 11,1 & 18,5 & 50,8 & 4,5 & 27,2 & 31,1 \\
\hline 4 & $\begin{array}{l}\text { Длиннокрылая } \\
\text { широколобка }\end{array}$ & 10,7 & 30,4 & - & 8,3 & 12,5 & 13,6 & 3,7 & 19,1 & - & 3,6 & 9,2 & 4,8 \\
\hline 5 & Род Batrachacottus & 21,4 & - & - & 41,7 & 4,2 & 13,6 & 4,1 & - & - & 24,7 & 5,8 & 6,7 \\
\hline 6 & Род Сурhocottus & 3,6 & - & - & - & - & - & 2,4 & - & - & - & - & - \\
\hline 7 & Ротан-головешка & 3,6 & - & 20 & 12,5 & 4,2 & 22,7 & 0,9 & - & 11,6 & 11,3 & 1,1 & 21,8 \\
\hline 8 & $\begin{array}{l}\text { Бычки, ближе } \\
\text { не определены }\end{array}$ & $\mid 10,7$ & - & 20 & - & 16,7 & 9,1 & 6,8 & - & 11,6 & - & 3,2 & 5,4 \\
\hline 9 & Плотва & 3,6 & - & 10 & - & 8,3 & - & 4,1 & - & 5,1 & - & 6 & - \\
\hline 10 & Омуль & - & - & - & - & 4,2 & - & - & - & - & - & 1,9 & - \\
\hline 11 & Хариус & - & 34,8 & - & 4,2 & - & - & - & 51,5 & - & 1,9 & - & - \\
\hline 12 & $\begin{array}{l}\text { Рыба, ближе } \\
\text { не определена }\end{array}$ & 25 & - & 15 & 4,2 & - & 13,6 & 17,9 & - & 11,1 & 1,4 & - & 5,4 \\
\hline
\end{tabular}

Таблииа 7

Характеристика питания птенцов большого баклана в дельте р. Селенги

\begin{tabular}{|c|l|c|c|c|c|}
\hline \multirow{2}{*}{ № } & \multirow{2}{*}{ Вид корма } & \multicolumn{2}{|c|}{ Встречаемость (\%) } & \multicolumn{2}{c|}{ Весовая доля (\%) } \\
\cline { 3 - 6 } & & 2019 & 2020 & 2019 & 2020 \\
\hline 1 & Омуль & 92 & 17,9 & 90,6 & 9,7 \\
\hline 2 & Ротан-головешка & 8 & 85,7 & 4,1 & 67,6 \\
\hline 3 & Окунь речной & - & 17,9 & - & 12,1 \\
\hline 4 & Плотва & 4 & 10,7 & 5,3 & 9,0 \\
\hline 5 & Карась & - & 3,6 & - & 1,6 \\
\hline
\end{tabular}




\title{
Заключение
}

Структура рациона большого баклана в гнездовой период на Байкале определяется местоположением колонии и, соответственно, экологическими условиями, сложившимися в данный момент в окружающих биотопах. Основу рациона бакланов составляет наиболее массовые, а следовательно, наиболее доступные виды рыб.

\section{Литература}

1. Мокридина М. С. Изменения в структуре питания рыбоядных птиц на Байкале как результат антропогенного воздействия на экосистему озера // Орнитологические исследования в странах Северной Евразии : тезисы XV Международной орнитологической конференции Северной Евразии, посвященной памяти академика М. А. Мензбира (165-летию со дня рождения и 85-летию со дня смерти). Иркутск : Аспринт, 2021. С. 26-27. Текст : непосредственный.

2. Пыжьянова М. С., Пыжьянов С. В., Ананин А. А. Большой баклан в Центральной Азии: динамика ареала в XX-XXI вв. // Экосистемы Центральной Азии в современных условиях социально-экономического развития : материалы международной конференции (Улан-Батор, Монголия, 8-11 сентября 2015 г.). Улан-Батор, 2015. С. 341-344. Текст : непосредственный.

3. Рябицев В. К. Птицы Урала, Приуралья и Западной Сибири. Екатеринбург : Изд-во Урал. ун-та, 2008. 633 с. Текст : непосредственный.

Статья поступила в редакиию 24.10.2020; одобрена после реценнирования 18.11.2021; принята к публикаиии 20.12.2021.

\section{FOODS OF GREAT CORMORANT ON LAKE BAIKAL AT THE CHICK'S FEEDING PERIOD}

\author{
M. S. Mokridina \\ Mariya S. Mokridina \\ Senior Teacher, \\ Irkutsk State University \\ 1 Karla Marksa St., Irkutsk 664003, Russia \\ rjs-92@mail.ru
}

Abstract. Data of feeding of Great Cormorant chicks are showing which collected in different regions of Lake Baikal (Maloye More, Selenga river delta, Baklaniy Kamen island in bay Pestchanaia vicinity) in 2017-2020. Position of colony stronger effected to differences of feeding than condition of different years. In breeding season the base of food at Maloye More is fish of bottom-dwelling species of Cottidae family and Perca fluviatilis, Leuciscus leuciscus and Rutilus rutilus. In Selenga delta the base of food is Perccottus glenii and the same species plus Carasius carasius. But at the time of visit of flocks of Omul Coregonus autumnalis migratorius most of cormorants change-over to feeding of this species. The widest specter of food of cormorant find at Baklanii Kamen island which can be explaining by specific position of this island. Seasonal fluctuation in feeding ration of cormorant is pointed at this island and in delta Selenga. 
Keywords: the Great cormorant, feeding period, Lake Baikal, Maloye More, Selenga delta, Baklaniy Kamen.

\section{For citation}

Mokridina M. S. Foods of Great Cormorant on Lake Baikal at the Chick's Feeding Period. Nature of Inner Asia. 2021; 4(19): 65-71 (In Russ.). DOI: 10.18101/2542-0623-2021-4-65-71

The article was submitted 24.10.2021; approved after reviewing 18.11.2021; accepted for publication 20.12.2021. 